\title{
O capitalismo e a educação
}

\section{Capitalism and education}

\author{
Quenízia Vieira Lopes ${ }^{1 *}$, Maiara Sobral Silva ${ }^{2}$, Adriana Regina de Jesus Santos ${ }^{1}$
}

\begin{abstract}
RESUMO
A história da educação no decorrer dos tempos tem sofrido influências políticas, econômicas, sociais e culturais impulsionadas pela conjuntura em que está introduzida. Os sistemas dominantes têm buscado com que a educação atue como instrumento auxiliador para que estes alcancem as suas finalidades. Em referência ao capitalismo identifica-se que para este a educação não é indiferente: também serve como ferramenta para que os seus interesses sejam alcançados, utilizando-a como um dos seus mecanismos de suporte. Assim, busca-se, por meio deste trabalho, realizar uma análise do capitalismo correlacionando-o com o contexto educacional na sociedade contemporânea, com vistas a identificar as interferências que a educação sofre na conjuntura correspondente. Percebe-se que a autonomia no contexto educacional é limitada, e quase sempre sofre pressões do sistema dominante. Depreende-se que a união e o entendimento de todos que compõem o processo educacional, em uma mesma direção, é fundamental para uma nova forma de conduzir o processo.
\end{abstract}

Palavras-chave: Educação; Capitalismo; Influência.

\section{ABSTRACT}

The history of education over time has suffered political, economic, social, and cultural influences driven by the context in which it is introduced. The dominant systems have sought for education to act as an auxiliary instrument for them to reach their goals. In reference to capitalism, we identify that for it education is not indifferent: it also serves as a tool to achieve its interests, using it as one of its support mechanisms. Thus, this paper seeks to analyze capitalism by correlating it with the educational context in contemporary society, in order to identify the interferences that education suffers in the corresponding conjuncture. It can be seen that autonomy in the educational context is limited, and is almost always pressured by the dominant system. It is understood that the union and understanding of all those who make up the educational process, in the same direction, is fundamental to a new way of conducting the educational process.

Keywords: Education; Capitalism; Influence.

\footnotetext{
${ }^{1}$ Universidade Estadual de Londrina (UEL).*E-mail: quenizia@gmail.com
}

${ }^{2}$ Universidade Federal de Uberlândia (UFU) 


\section{INTRODUÇÃO}

Em uma análise sobre a história da educação no decorrer dos tempos é possível verificar como esta tem sofrido influências políticas, econômicas, sociais e culturais impulsionadas pela conjuntura em que está introduzida. Cada vez mais os sistemas dominantes têm buscado com que a educação atue como instrumento auxiliador para que estes alcancem as suas finalidades.

Em referência ao capitalismo percebe-se que para este a educação não é indiferente: também serve como ferramenta para que os seus interesses sejam alcançados, utilizando-a como um dos seus mecanismos de suporte. Verificando os fatos históricos em comparação ao contexto educacional, constata-se, por exemplo, que as reformas do Estado ocorridas no decorrer dos acontecimentos consagrados no Brasil acabaram implicando nos aspectos educacionais. Um desses fatores pode ser certificado pela efetivação da Lei de Diretrizes e Bases da Educação Brasileira, lei que estabelece as diretrizes e bases da Educação Nacional, que começou a ser discutida e elaborada em 1988, sendo emitida somente em 1996, por meio da Lei n. ${ }^{\circ} 9.394$, de 20 de dezembro de 1996.

Desta forma, busca-se, por meio deste trabalho, realizar uma análise do capitalismo correlacionando-o com o contexto educacional, com vistas a identificar as interferências que a educação sofre com as transformações econômicas, sociais, políticas e culturais da conjuntura correspondente.

O trabalho está dividido em duas seções: O capitalismo e A influência do contexto contemporâneo na Educação. Nessa conjectura, entende-se que estudar a interrelação entre o capitalismo e o modelo educacional contemporâneo é importante para desvelar as lógicas neoliberais presentes na educação.

\section{O CAPITALISMO}

Registra-se que o sistema feudalismo, que perdurou até o século $\mathrm{XV}$, em que a nobreza era considerada como a autoridade superior e tinham os servos sob sua subordinação, foi o que antecedeu o capitalismo, que é um sistema que visa sempre o ganho, o lucro, o acúmulo de riquezas mantendo a ordem do capital, e que originou-se a partir da ruptura senhorio e servidão, em que novas formas de organização do trabalho 
são criadas, a partir de um sistema de troca de mercadorias. Conforme disposto Libâneo et. al (2012, p. 82), o capitalismo pode ser assim definido:

Denominação do modo de produção em que o capital, sob suas diferentes formas, é o principal meio de produção. Tem como princípio organizador a relação entre trabalho assalariado e o capital e como contradição básica a relação entre produção social e produção privada.

Para Marx (1985), o capitalismo surge a partir da produção e circulação de mercadorias, que ao final desse processo alcança o capital, sendo o dinheiro o precursor da materialização do capital, em outras palavras, o capital assume a forma de dinheiro. Assim, nesse processo de produção e circulação há um círculo que se origina na mercadoria, que é produzida e posteriormente comercializada, tendo como produto do seu comércio o capital, que neste caso é o dinheiro, e que com vistas a gerar mais riquezas, reinicia um novo ciclo proporcionando nova produção e circulação de mercadorias. Contudo, o círculo invertido também pode existir, em que a mercadoria acaba sendo realizada posteriormente ao capital, em que o início e o fim será o dinheiro. No primeiro ciclo, de acordo com Marx, o valor de uso será seu fim último, já no segundo será o valor de troca.

Como o capitalismo visa o lucro, a riqueza, quando em seu processo de circulação de mercadorias há trocas com valores equivalentes, não há geração de riqueza, isto posto, não gera mais-valor, o que de certa forma não alcança o fins deste sistema. E é nesse contexto que surge um tipo de mercadoria que é visionada pelos capitalistas, que são os detentores do dinheiro e do meios de produção, para que esses alcancem suas lucratividades: a força de trabalho, que é fonte de valor, e que só é considerada mercadoria a partir do momento que o indivíduo se dispõe a comercializá-la em troca de capital. O indivíduo comercializa sua força de trabalho com vistas a suprir as suas necessidades básicas com o capital recebido em troca daquela.

De acordo com Marx (1985), o trabalho é a ação do homem sobre a natureza. Para a construção do valor, em torno da produção e comercialização de mercadorias, envolvese: o valor da força de trabalho, o valor de uso, o valor de troca e o preço final do produto comercializado. Com vistas a obtenção de lucros, o possuidor do processo de produção faz com que o trabalhador realize suas atividades, em determinado período de tempo, em que ele próprio consiga suprir, pelo valor do seu trabalho realizado, isto é, o valor que será pago pela sua força de trabalho pelo capitalista, com um excedente, ou seja, ao final 
do processo o capitalista irá pagar o trabalhador com o lucro gerado pela força de trabalho dele e ainda lhe restará um saldo, juntamente com o valor aplicado no valor do produto. Neste processo é definido o conceito de mais-valia. Para Libâneo et. al (2012, p. 82), mais-valia pode ser definido como "apropriação, por parte do capitalista, do valor produzido pelo trabalhador para além do trabalho necessário à subsistência".

Destarte, diante desta conjuntura, destaca-se pontos importantes no capitalismo: seus principais elementos são o trabalho assalariado, a propriedade privada dos meios de produção e lutas por mercado. Além disso, para produzir riquezas no capitalismo é necessário a depredação da natureza, além da exploração do trabalho, como garantia para gerar mais capital. Realizando uma análise crítica da economia política, Marx descreve que,

\footnotetext{
Não se compreende a renda da terra sem o capital, entretanto compreende-se o capital sem a renda da terra. O Capital é a potência econômica da sociedade burguesa que domina tudo. Deve constituir o ponto inicial e o ponto final a ser desenvolvido antes da propriedade da terra. Depois de considerar particularmente um e outro, deve-se estudar a sua relação recíproca. (MARX, 1978, p. 122).
}

Esse Capital enquanto dominante do sistema perpassa todas as relações, ele possui o controle sobre indivíduos e suas totalidades. Cabe destacar que "o princípio fundamental do capitalismo é a santificação do lucro privado (ou corporativo) baseado na apropriação do trabalho excedente (o tempo de trabalho não pago) definido como o valor excedente da força de trabalho" (HILL, 2003, p. 26, ).

O Capitalismo vem mudando sua configuração no decorrer dos tempos. Distingue-se, conforme disposto por Libâneo et. al. (2012), quatro fases diferentes no seu percurso, com relação a sua forma de produção: 1) a mercantil, comercial ou concorrencial (Século XVIII e início do século XIX); 2) segunda Revolução Industrial, imperialista ou monopolista (Século XIX e início do século XX); 3) monopolista de Estado, Estado benfeitor ou Neoliberalismo social-democrata (Século XX - Pós-Segunda Guerra Mundial); e 4) concorrencial global, neoliberalismo de mercado ou terceira Revolução Industrial (Século XX - início da década de 1980).

Vale ressaltar que o capitalismo teve seu auge registrado nos anos 50, contudo, por volta dos anos 70, teve um registro de longa e profunda recessão. Quando refere-se a uma crise no capitalismo, expõe-se que houve excesso na produção, isto é, o que é produzido não se consegue dar vazão, a sociedade não consegue consumir. Portanto, a 
crise do capitalismo se dá em decorrência do excesso de produção, o que difere de outros contextos em que é relatado uma crise, sendo que quando isso ocorre é por escassez de algo. Outrossim, quando explana-se crise no capitalismo é afirmado que há uma crise estrutural, que também pode ser considerada cíclica, à medida que gira em torno da mercadoria e dos benefícios monetários que ela gera.

Um fator importante a se registrar é que, por necessidade de manter o capital, por ajustes de salários, para manutenção da procura e da oferta, o desemprego acaba por ser necessário no sistema do capitalismo, aquiescendo com o disposto por Libâneo ao afirmar que,

As relações sociais no capitalismo são, assim, fortemente marcadas pela divisão da sociedade em classes, onde capitalistas e trabalhadores ocupam lugares opostos e antagônicos no processo de produção. A classe social proprietária dos meios de produção retira seus lucros da exploração do trabalho da classe trabalhadora. Esta, à qual pertencem cerca de $70 \%$ da população brasileira, é obrigada a trocar sua capacidade de trabalho por um salário que não cobre as suas necessidades vitais e privada, também, da satisfação de suas necessidades espirituais e culturais. A alienação econômica dos meios e produtos dos trabalhadores, que é ao mesmo tempo alienação espiritual, determina desigualdade social e consequências decisivas nas condições de vida da grande maioria da população trabalhadora. Este é o traço fundamental do sistema de organização das relações sociais em sociedade. (LIBÂNEO, 1994, p. 19-20).

Nos anos 70, o Neoliberalismo, que é organizado para combater o Keynesianismo, o estado do bem-social e o solidarismo (coitadismo), ou seja, uma sociedade para questões sociais, e possibilita ou cria especulação financeira, conteve os altos índices de inflação, e esse sucesso se deu, em parte, à derrota do movimento sindical, o que também gerou o aumento no número de desempregados, a queda na tributação de salários e o aumento nos valores de bolsa. Porém, essas ações foram realizadas para reanimação do capitalismo avançado mundial, que culminou com o aumento de taxas como anteriormente já haviam sido realizados. (ANDERSON, 2005).

Nos anos 80, de acordo com Anderson (2005), o Neoliberalismo também se torna mais forte, de acordo com as ações praticadas por seus governos, como a implantação de programas de privatização, disciplina orçamentária e reformas fiscais. Na década de 80 , no Brasil, é identificável a saída do período ditatorial, e nesse período, em relação à situação econômica, o traço marcante é o desenvolvimentismo. Nessa época as crises sobre o capitalismo foram se ampliando, fazendo com que organismos internacionais, 
também chamados de organismos unilaterais, dentre eles o Banco Mundial, pressionassem os países para que realizassem suas reformas, entre essas, a reforma do Estado, isto é, a redefinição do papel do Estado.

Desde o final do século XX, o capitalismo tem sofrido reestruturação, impulsionada pelo avanço tecnológico e científico no mundo, que influencia diretamente no seu modo de concretização. Além disso, é possível afirmar, de acordo com a análise do processo do capitalismo, que o cenário político atual é uma estrutura guiada pelo próprio do capitalismo. Com o surgimento da globalização, que conforme Libâneo et. al. (2012, p. 85), "pode ser entendida como uma estratégia de enfrentamento da crise do capitalismo e da constituição da nova ordem econômica", há uma maior abertura para o mercado competitivo, não carecendo da regulação do estado, e possibilitando uma maior organização do capitalismo.

Para alcançar essa tal organização, o capitalismo traz elementos do modelo gerencial, ou seja, aproxima-se da Administração Pública com os conceitos do mercado, cujo alguns dos critérios são: controle, rankings, metas, resultados, entre outros. De acordo com Freitas (2016, p. 140):

O modelo de gestão considerado eficaz é o da iniciativa privada, cujo centro está baseado em controle e responsabilização, ou seja, em processos de fixação de metas objetivas submetidas a avaliação e divulgação, associadas a prêmio ou punição, na dependência dos resultados obtidos. Os supostos básicos do seu bom funcionamento são o controle gerencial e a concorrência sob as leis do mercado. Na área pedagógica, esse modelo alinha objetivos de aprendizagem previamente definidos com o processo de ensino e com a avaliação sistemática e frequente desses objetivos.

Entende-se que assim como o sistema do capitalismo sofre influências pelo contexto de transformações técnicas-científicas, a Educação também recebe influências, e mais ainda porque envolve outros contextos como os sociais, políticos, econômicos e culturais, que são, de certa forma, conduzidos pelo sistema dominante vigente, destacando-se no corrente o próprio sistema capitalismo. Assim, a seguir, explorar-se-á sobre alguns dos impactos gerados sobre o ambiente educacional pela conjuntura contemporânea. 


\section{A INFLUÊNCIA DO CONTEXTO CONTEMPORÂNEO NA EDUCAÇÃO}

As ideologias impostas pelo capitalismo requer do sujeito a aquisição de novos conhecimentos e, nessa conjuntura, a educação torna-se um força motriz para auxiliar no processo, sendo necessário desta uma adaptação teórica e prática das atividades praticadas, com vistas a se convencionar a exigência dos movimentos emergentes da prática educacional com às novas ideologias, principalmente as que direcionam para $\mathrm{o}$ papel social em contraponto às ideologias de mercado.

Contribuindo com essa reflexão, numa das poucas passagens em que se referiu especificamente à necessidade da educação em sua obra "Ontologia do Ser Social", Lukács (2013) pondera que os animais adultos auxiliam seus filhotes para que se apropriem de comportamentos e destrezas necessárias para a sua vida toda. Entretanto, argumenta Lukács (2013) que “o essencial da educação dos homens, pelo contrário, consiste em capacitá-los a reagir adequadamente aos acontecimentos e às situações novas e imprevisíveis que vierem a ocorrer depois em sua vida.” (LUKÁCS, 2013, p. 130). Este complexo necessário chamado educação se manifesta no ser social de duas maneiras: de um modo amplo (aprender a viver em sociedade) e de uma maneira estrita (capacitando para o exercício específico de um papel social). Apresentando essa questão da educação no sentido mais amplo, Saviani (2007) exemplifica o encadeamento produção/formação do Ser Social na seguinte citação:

Se a existência humana não é garantida pela natureza, não é uma dádiva natural, mas tem de ser produzida pelos próprios homens, sendo, pois, um produto do trabalho, isso significa que o homem não nasce homem. Ele forma-se homem. Ele não nasce sabendo produzir-se como homem. Ele necessita aprender a ser homem, precisa aprender a produzir sua própria existência. Portanto, a produção do homem é, ao mesmo tempo, a formação do homem, isto é, um processo educativo. A origem da educação coincide, então, com a origem do homem mesmo. (SAVIANI, 2007, p. 154).

Dessa forma, a educação nunca será concluída, nem no sentido amplo e nem no sentido estrito. Lukács (2013) exemplifica esse segundo sentido quando argumenta que a vida do homem, "dependendo das circunstâncias, pode terminar numa sociedade de tipo bem diferente e que lhe coloca exigências totalmente distintas daquelas, para as quais a sua educação - sentido estrito - o preparou." (LUKÁCS, 2013, p. 130). O ser social se 
constitui complexo e mutável, logo, a capacitação (Educação) do homem, precisa se manter initerruptamente porque a sociedade dialeticamente está sempre em movimento.

Na conjuntura do Neoliberalismo, com a implementação de política econômica mundial, a escola sofre influências. Com o avanço do discurso econômico do Neoliberalismo, cria-se condições políticas para globalização, e os organismos multilaterais vinculados ao capitalismo, influenciam diretamente sobre contexto educacional.

Isso posto, por decorrência da história, a sociedade e a educação se dividiram, ou seja, Manacorda (1989) e Saviani (2007) avaliam que com o desenvolvimento da sociedade de classes se efetivou o desmembramento e a depuração de processos educativos diferenciados para os coletivos opostos que passam a reproduzir a sociedade. Em sua "Ontologia” Lukács (2013) já explicava que cada tipo de sociedade demanda de determinados tipos de capacidades de seus indivíduos e ai surge a educação de modo estrito, formal ou institucionalizada. Uma teleologia secundária que precisa responder a uma demanda.

Nesse sentido, entendendo a explanação da "Ontologia" Lukácsiana, Saviani (2007) vem argumentar sobre as origens da institucionalização da educação com o desenvolvimento da sociedade de classes, confinada num tempo e espaço específico intitulado escola, observando que:

Se nas sociedades primitivas, [...] a educação consistia numa ação espontânea, [...] com a divisão dos homens em classes a educação também resulta dividida; diferencia-se, em consequência, a educação destinada à classe dominante daquela a que tem acesso a classe dominada. E é ai que se localiza a origem da escola. A educação dos membros da classe que dispõe de ócio, de lazer, de tempo livre passa a organizar-se na forma escolar, contrapondo-se à educação da maioria, que continua a coincidir com o processo de trabalho. (SAVIANI, 2007, p. 155).

A propriedade privada gerou divisão dos homens e teve efeitos na própria compreensão ontológica do homem, pois com seu advento tornou-se possível à classe dos proprietários viverem sem trabalhar, "dispondo do ócio, do lazer e do tempo livre" como mencionado por Saviani (2007). Também Manacorda (1989) vem lembrar que as sociedades da antiguidade, no Egito por exemplo, aproximadamente a 2.500 anos a.C., já se vivia a experiência de uma civilização estratificada em hierarquias, que careciam cada 
qual, de certos conhecimentos específicos. Aos dominantes da antiguidade, assinala o autor, impelia a necessidade de "falar bem".

Nesse contexto, exigia-se a presença de certos indivíduos com tal capacidade e dispostos à finalidade de capacitar outros mais a reagirem adequadamente às situações imprevisíveis que iriam surgir, respondendo com as habilidades as quais foram qualificados.

Faz-se necessário ressaltar que, tendo por base a História do Ocidente, pode-se afirmar que em toda a antiguidade, no período medieval e também o período da modernidade, que se inicia no final do século XV indo até meados do século XVIII, que a educação para o trabalho intelectual fica restrita a uma pequena parcela de indivíduos que compunham a elite. Porém, na idade moderna com o início da sociedade capitalista, mediante as relações do capitalismo mercantil, e também sobre influência da reforma protestante, um novo cenário surge para a educação, que vai se tornando uma necessidade crescente para cada vez mais indivíduos, pessoas comuns, pudessem aprender a matemática, ler e escrever. Contudo, é na idade contemporânea, desde as revoluções do século XVIII até os nossos dias, que se apresentaram grandes mudanças no papel que foi atribuída a escola na formação dos indivíduos.

Ciente de que "toda sociedade reivindica certa quantidade de conhecimentos, habilidades, comportamentos, etc.” (Lukács, 2013), Saviani (2007) vem explicar que as revoluções Francesa, tomada do poder pela burguesia em 1789 e nesse mesmo período a Industrial na Inglaterra, com a introdução da máquina no processo produtivo, como eventos processuais que marcaram a entrada desta nova sociedade, acabam também por tornar-se decisivos para a institucionalização da escola, pois:

[...] a estrutura da sociedade deixa de fundar-se em laços naturais para pautar-se por laços propriamente sociais, isto é, produzidos pelos próprios homens. Trata-se da sociedade contratual, cuja base é o direito. Com isso, o domínio de uma cultura intelectual, cujo componente mais elementar é o alfabeto, impõe-se como exigência generalizada a todos os membros da sociedade. E a escola, sendo o instrumento por excelência para viabilizar o acesso a esse tipo de cultura, é erigida na forma principal, dominante e generalizada de educação. (SAVIANI, 2007, p. 158).

Destarte a partir do capitalismo por meio da Revolução Industrial Saviani afirma que: 
Os principais países assumiram a tarefa de organizar sistemas nacionais de ensino, buscando generalizar a escola básica. Portanto, à Revolução Industrial correspondeu uma Revolução Educacional: aquela que colocou a máquina no centro do processo produtivo $(2007$, p. 159).

Dessa maneira a sociedade em que vivemos é, antes de mais nada, uma sociedade capitalista, em que o elemento econômico subordina todas as dimensões da vida humana. Segundo Theis (2002) com a globalização da economia capitalista e a adoção de políticas neoliberais, ficou demarcada o ideário em concepções pedagógicas alienantes como "competências" e "habilidades", pedagógico neoliberal. Sendo assim, os princípios educacionais passam a ser produtividade e competitividade.

Destaca-se que com a política do Neoliberalismo exige-se trabalhador mais flexível e polivalente, isto é, que consiga se adaptar ao contexto e desenvolver muitas atividades. Assim, a educação, de certa forma, é demandada e ao mesmo tempo valorizada como formadora de novas habilidades cognitivas e competências sociais e pessoais que esse contexto exige. Veja:

Nesse contexto, o Brasil vem implementando desde os anos 90 do século XX, suas políticas econômicas e educacionais de ajuste, ou seja, diretrizes e medidas pelas quais o país se moderniza, adquire as condições de inserção no mundo globalizado e, assim, se ajusta às exigências de globalização da economia. (LIBÂNEO et. al. , 2012, p. 66)

Evidencia-se, conforme disposto por Libâneo et. al. (2012), que a modernização econômica capitalista, pós-Segunda Guerra Mundial, demandou outras ações do contexto educacional tendo em vista as mudanças na economia e no mercado de trabalho, quais sejam: formação de sistemas nacionais de ensino; busca pela igualdade de acesso ao ensino, bem como a Universalização do ensino, com vistas a possibilitar o estabelecimento de condições de instituição da sociedade democrática, moderna, científica, industrial e plenamente desenvolvida. Portanto, busca-se facilitar a seleção dos indivíduos no contexto, ou seja, integrá-los de forma igualitária e mais natural para beneficiar os objetivos da modernização econômica da época.

Hoje ao se falar da universalização do ensino há um foco sobre o ensino fundamental, visto que, de acordo com Libâneo et. al. (2012, p. 105), “(...) agora se faz uso do discurso da eficiência e da qualidade para conter a expansão educacional pública 
e gratuita, sobretudo no ensino superior, tendo como fim outro projeto de modernização econômica".

Uma das orientações emanadas pelo Banco Mundial quanto a organização do contexto educacional ao sistema vigente, é que a educação se integre nesse processo sistêmico, que oferte o ensino de forma mais eficiente, também com qualidade, integrada ao novo contexto tecnológico, sendo de excelência e qualidade total, tendo uma administração eficiente para melhor desenvolver o controle do processo.

A escola, por sua vez, acaba tendo que adequar suas finalidades aos interesses de mercado, uma vez que sofre as pressões do sistema de poder vigente. Com isso, o objeto da escola, os seus interesses, as suas prioridades, necessidades e valores são modificados, para atendimento das finalidades de demanda de mercado, uma vez que a exigência é de maior eficiência e qualidade dos indivíduos, o que acarreta essa demanda de formação do indivíduo sobre a escola.

Não se pode deixar de evidenciar que a educação tem seu papel relevante na sociedade à medida que possibilita o apoderamento de conhecimentos historicamente sistematizados, que auxiliam no desenvolvimento do pensamento, com prevalência dos conceitos científicos, isto é, conceitos elaborados, sob os conceitos espontâneos, instituindo sujeitos críticos e participativos.

No contexto da sociedade atual, com um novo paradigma instituído quanto ao sistema de produção, que demanda ainda mais adaptação, as escolas tendem a acompanhar esse processo, principalmente no contexto do avanço tecnológico, portanto, essas introduzem novas práticas envolvendo o avanço das tecnologias e comunicação, e com isso novas condutas cotidianas são implementadas.

Ressalta-se que o avanço da tecnologia demanda-se importantes mudanças no contexto educacional. Constata-se que com os avanços tecnológicos e a reestruturação sócio-econômica também recaem sobre a educação responsabilidades, como incluir alunos e professores no contexto tecnológico, realização de avaliações do sistema educacional e dos envolvidos nesse processo; e sacrifícios, como a redução de recursos e a responsabilização do professor pelo fracasso do aluno. Contudo, destaca-se que, no processo educacional, nem todo trabalho realizado eleva o sujeito ao patamar de evolução master do seu desenvolvimento.

Nessa conjuntura, considera-se que os professores também devem estar preparados a praticarem novas metodologias que incluam esse universo de avanço da 
comunicação tecnológica. E para que isso se concretize, é necessário uma reestruturação tanto da sua prática como da teoria, para melhor articular-se a formação dos indivíduos, para que esses sejam cidadãos mais críticos e participativos, que consigam desenvolver atividades de forma mais autônoma, que consigam, por exemplo, analisar determinada situação, e sobre esta ter o seu próprio entendimento e assim tomar decisão de forma consciente e ética. Portanto, cidadãos que consigam se integrar ao novo contexto social, entre eles o mercado profissional de trabalho.

A expansão da educação e do conhecimento, necessária ao capital e à sociedade tecnológica globalizada, apoia-se em conceitos como modernização, diversidade, flexibilidade, competitividade, excelência, desempenho, ranking, eficiência, descentralização, integração, autonomia, equidade, etc., conforme descrito por Libâneo et. al. (2012).

É primordial a reflexão em torno do desenvolvimento humano, e nesta conjuntura uma análise do papel da educação nesse desenvolvimento, uma vez que o ensino deve ser organizado e intencional no intuito de produzir a evolução do indivíduo. Nesse sentido, conclui-se que é imprescindível preparar o sujeito para esse novo universo produtivo, isto é, uma formação escolar que o capacite para o desenvolvimento de diferentes habilidades para que assim ele possa acompanhar as exigências atuais da contemporaneidade, pois o homem é um ser social e, de acordo com as atividades que ele desenvolve em um determinado contexto, os seus conhecimentos vão se ampliando, à medida de suas experiências realizadas.

Ainda nesse sentido, faz-se necessário pensar sobre:

[...] a intervenção positiva da educação na elaboração na elaboração dos meios de contrapor-se com êxito à dominação global do capital, pelo estabelecimento das formas organizacionalmente viáveis de solidariedade socialista, é vital para o cumprimento do grande desafio internacional de nosso tempo histórico.(MÉSZÁROS, 124).

Desta forma, por mais que o sistema neoliberal insista em aproximar o capital da educação, é necessário instigar uma educação que vá além desse capital, que reconheça os indivíduos em sua totalidade e não apenas pela sua alienação às lógicas do sistema capitalista. 


\section{CONSIDERAÇÕES FINAIS}

A aproximação entre o capital e a educação precisa ser repensada, tendo em vista que "para os neoliberais, o lucro é Deus, não o bem público. O capitalismo não é, essencialmente, bondoso. [...] No capitalismo, o motor das políticas públicas é a demanda insaciável pelo lucro, não a riqueza, o bem público social ou comum. (HILL, p.26).

Ainda nesse sentido, o capitalismo, por ser um sistema que busca organizar a estrutura social por meio dos modos de produção, que tem como foco o acúmulo de riquezas e que explora a natureza e o trabalho para o alcance da sua finalidade, tendo como umas de suas características a divisão de classes sociais, dificilmente será vencido por um novo sistema em que não se tenha como base o capital. Este pensamento se deve ao fato que, apesar da sociedade contemporânea sofrer exploração neste sistema por meio do seu trabalho, do mesmo modo que por outros fatores a este relacionado, já tomou para si o capital como fonte de resolução para a maioria das problemáticas reveladas.

Por consequência, nessa perspectiva, os integrantes da sociedade não se vislumbram como mais importantes do que o próprio capital gerado, isto é, o sujeito tem um olhar de que o que mais vale no mundo atual é o capital existente, em outros termos, aquilo que é possível adquirir por meio dele, e não a sua própria existência, o que de fato esse ser representa no contexto, deixando-se permanecer dominado pelo poder existente por não se reconhecer como o bem mais valioso que é capaz de mudar o contexto e o rumo da história.

A educação, mais especificamente a escola, é um ambiente de reprodução, que serve para auxiliar na manutenção do sistema vigente, na ordem social, ou seja, contribuir na forma de poder com que se identifica. Sob outra perspectiva, entende-se que também é considerada como um espaço de possibilidades de transformação, uma vez que exerce suas ações, que são políticas, e por meio delas pode coadjuvar com as relações de poder ou até mesmo esquivar-se delas. Assim, faz-se necessário uma reflexão constante das suas atividades, das suas finalidades, para contribuir com fins objetivados pelos quais se assemelha, com um olhar voltado para o desenvolvimento de uma sociedade mais justa e participativa.

Todavia, é perceptível que a autonomia no contexto educacional é limitada, e quase sempre sofre pressões do sistema dominante para que suas ações sejam condizentes com os interesses desse. Entretanto, é necessário o entendimento que mudanças só serão 
possíveis com lutas, e desta forma, é essencial ser resiliente na primordialidade, visando sempre o bem maior da sociedade, visto que, por meio do processo educacional é possível auxiliar na visualização das necessidades dos seres humanos e assim possibilitar as transformações da sociedade.

Por fim, entende-se que a união e o entendimento de todos que compõem o processo educacional, em uma mesma direção, é fundamental para concretização desse novo olhar sobre o sistema vigente e uma introdução de uma nova forma conduzir o processo educacional, tendo como foco principal a qualidade do processo ensino aprendizagem, com vistas a formar integralmente o cidadão, para que esse se torne cada vez mais consciente, responsável, ético, detentor de amplos conhecimentos, crítico e participativo no contexto social, uma vez que, para que a sociedade seja transformada é necessário que o ser humano seja também modificado, tanto em suas relações sociais com outros indivíduos como também na compreensão de tudo que o cerca.

\section{REFERÊNCIAS}

ANDERSON, Perry. Balanço do Neoliberalismo. In: GENTILI, P. ; SADER, E. (Org.). Pós-neoliberalismo: as políticas sociais e o Estado democrático. São Paulo: Paz e Terra, 2005. p. 9-23.

FREITAS, L. C. de. Três teses sobre as reformas empresariais da educação: perdendo a ingenuidade. Cad. CEDES [online]. v.36, n.99, pp.137-153, 2016. DOI:

10.1590/CC0101-32622016160502. Acesso em: 15 maio. 2021.

HILL, Dave. O neoliberalismo global, a resistência e a deformação da educação.

Currículo sem Fronteiras, [s.1.], v. 3, n. 2, p. 24-59, jul./dez. 2003.

LIBÂNEO, José Carlos. Didática. 2009. 29ª reimpressão. São Paulo: Cortez, 1994.

LIBÂNEO, José Carlos; OLIVEIRA, João Ferreira de; TOSCHI, Mirza Seara.

Educação escolar: políticas, estrutura e organização. São Paulo: Cortez, 2012.

LUKÁCS, György, Para uma ontologia do ser social, II. Tradução Nélio Schneider, Ivo Tonet, Ronaldo Vielmi Fortes. São Paulo: Boitempo, 2013.

MANACORDA, M. A. História da educação: da Antiguidade aos nossos dias. São Paulo: Cortez/Autores Associados, 1989.

MARX, Karl. Para a crítica da economia Política. In: Manuscritos econômicosfilosóficos e outros textos escolhidos. Seleção de textos de José Arthur, traduções de José Carlos Bruni et. al. $2^{\text {a }}$ ed. São Paulo: Abril Cultural, 1978. p. 116-123. 
MARX, Karl. O capital: crítica da economia política. Volume I. São Paulo: Nova Cultural, 1985.

MÉSZÁROS, I. A educação para além do capital. 2. ed. Tradução Isa Tavares. São Paulo: Boitempo, 2005. 128 p.

SAVIANI, Dermeval. Trabalho e educação: fundamentos ontológicos e históricos. Revista Brasileira de Educação, Rio de Janeiro, v. 12, n. 34, p. 152-165, jan./abr. 2007.

Recebido em: 01/09/2021

Aprovado em: 20/09/2021

Publicado em: 27/09/2021 